\title{
Scale and spatial representation: Restructuring of administrative boundary and GIS mapping in Bajhang district, Nepal
}

\author{
Shobha Shrestha \\ Central Department of Geography, Tribhuvan University, Kathmandu, Nepal \\ Email: shova216@gmail.com
}

\section{Abstract}

Census and other socio-economic surveydata collected athousehold and settlement level are aggregated and results are presented for specific administrative units. The wide and increasing availability of census and socio-economic data, tools like GIS with an ease to use and advances in methodology has allowed increasing and refined GIS mapping of census variables. However, it is less emphasized that the result of analysis and presentation is always dependent on the unit of analysis. Data aggregation, choice of data classification method and spatial scale all have effect on mapping result. When administrative boundaries are restructured, it necessitates the aggregation of census data of one administrative level to another. In this context, the current paper explores the scale and zoning effect (changing boundary, changing number of units and data aggregation) on mapping census data. It explores the effect of four data classification methods at two spatial scales. Secondary data sources like local administrative boundary of Bajhang district and economically active population in agriculture is selected as representative census variable for mapping. GIS tool is applied for data mapping and analysis. The study found the higher calculated correlation value (0.88) for the restructured spatial units. The distribution of number of spatial units varied significantly between four data classification methods while plotted against the old boundary but there was not much variation in case of newly restructured boundary. The study found that zoning particularly, from smaller to larger units has blurred the spatial pattern visualization leading to a loss of the preferential information. The study concludes that the restructuring of administrative boundaries into larger unit has simplified the detail for spatial representation and has introduced additional generalization. For policy level analysis, use of data 
available at one level of the spatial unit when aggregated to higher level should be analyzed carefully using different data classification methods and visualization tools because scaled spatial representation matters in planning and policy aspect. It is meaningful to analyze data at different spatial scale to visualize and identify spatial variation.

\section{DOI: http://dx.doi.org/10.3126/gjn.v12i1.23413}

Keywords: modifiable areal unit problem, boundary restructuring, data classification, spatial pattern

\section{Introduction}

Census and other socio-economic survey data collected at household and settlement level are aggregated and results are presented for specific administrative units. These data are utilized by various organizations for project planning, policy implementation and research purposes. The use and usefulness of census and other socio-economic survey data is well documented (Fox, 2010). The division of administrative units into sub units is important for policy and project planning and implementation activities. In order to analyze and evaluate existing development activities and plan for future, aggregated data needs to be integrated in such a manner that, data can be used at different spatial and temporal scales (Cheng, Turkstrab, Pengc, Dud \& Ho, 2006).Yet, integration of data at spatial scale can be difficult if the spatial boundaries are incompatible between different censuses. Long term comparative analysis of administrative unit is difficult because boundaries are restructured (Wall, 2008).

The wide and increasing availability of socio-economic, census and ecological data in aggregated form, tools like GIS with an ease to use and advances in statistical methodology has allowed a more refined analysis (Wakefield \& Lyons, 2010). A map is one of the most common methods of spatial representation of census data (National Research Council, 1997).It is also one of the common tools for planning and decision making in the development context such as identifying spatial variation in poverty, analyzing accessibility or identifying a suitable area for specific development intervention (Jelinski \& Wu, 1996; Wong, 2003; Bell \& Schuuman, 2010).However, the result of analysis and presentation is always dependent on the unit of analysis either it is an arbitrary unit like a spatial grid or existing spatial unit like an administrative or political boundary. Analysis and presentation results evident at one level of spatial unit changes with different spatial zoning and the sensitivity of the results to the definition of a spatial unit of analysis is one of the well-known methodological issues (Paez \& Scott, 2005). This is referred to as modifiable areal unit problem (MAUP), the methodological issue described by Gehlke and Biehl(1934) and the term first introduced by Openshaw 
and Taylor(1979).Two important features of MAUP are Scale effect and Zoning effect. Scale effect refers to the effect on the result when the same data are organized and analyzed into different spatial scale. Zoning effect on the other is the effect on the result of the analysis when the same spatial extent is subdivided differently (Wong, 2009). Not related to MAUP, but equally important is the effect of applying different data classification methods while GIS mapping.

Issues related to effect of scale and aggregation zones on mapping are not emphasized and analyzed though it is very important (Openshaw, 1996) and spatial analysis is performed with very less regard for the basic spatial representation issue which may impact the policy and planning decisions. Geographers have ignored the importance of spatial representation in analyzing and describing socio-economic data and the effect of scale and zoning (Openshaw \& Alvanides, 2005). A spatial level which is chosen for describing a phenomenon or representation plays the role of a filter and is very important from a policy and planning perspective (Veldhuizen \& Pfeffer, 2016). A multi-level representation is very useful at a policy level to apprehend how maps complement each other, from one level to another for identifying spatial variations (ESPON, 2006).

The new constitutional provision of Nepal 2015, has provided a spatial framework which led to restructuring of administrative boundaries. Restructuring of boundaries at subnational level as province and district and municipality and rural municipality at local level is implemented and followed for administrative and legislative powers (MoLJPA, 2017). It has now 753 local units with 461 rural municipalities and 292 municipalities which includes 6 metropolitans, 11 sub-metropolitans and 275 municipalities replacing prior local units of 3157 village development committees (VDCs) and 217 municipalities (MoFALD, 2018). Rural municipalities and municipalities are comprised of number of wards. Ward is still the lowest level administrative units and significant for local administration and services but it is not dissemination unit for published census data. Spatial unit for published census data was VDC till 2011. The national population census took place in 2011 and data were collected and presented using existing local units (VDCs) prior to restructuring. The new local units are created merging either part or whole of old VDCs and municipalities. This has necessitated the aggregation of census data of one administrative level to another for different study purposes. Hence, geographic scale and adjacency issues arouse as a result of the mapping depends on aggregated data and the associated spatial boundaries due to this new restructuring. In this context, the current paper explores the scale and zoning effect (changing boundary, changing number of units and data aggregation) on mapping census data based on the scale at which the spatial entities are observed, aggregated and analyzed. The paper also explores the visual effect of different data classification methods with the restructuring of the administrative boundary at the local level. Local administrative unit's boundary of Bajhang district is selected to explore the scale and data classification effect. 


\section{Material and methods}

\section{Study area}

Local level administrative boundaries of Bajhang district before and after restructuring is selected to explore the effect of scale and zoning on mapping census data. Bajhang is one of the remote mountain district which lies in the far western region of Nepal. The district falls in three physiographic regions namely Mountain (10\%), high Mountain (44\%) and high Himalaya region (46\%). Elevation of the district ranges from 915 meter in the south to 7035 meter in the north from the mean sea level. The district covers 3422 $\mathrm{Km}^{2}$ area and comprises 195159 population having population density of 57 persons per $\mathrm{Km}^{2}$ (DDC, Bajhang, 2014). Forest covers more than 55 percent of the total area and only 10 percent of the area is under cultivation. Though cultivation land is limited, agriculture is the major occupation of more than 80 percent of the total population. Out of the total population above 10 years, 66 percent are economically active and of the total economically active population, 85 percent are in agriculture. It is one of the five districts of the country having lowest HDI value (DDC Bajhang, 2014). The district had 47 local units till 2015 and each of these units was comprised by nine wards which changed to 12 units ( 2 municipalities and 10 rural municipalities) after restructuring of local boundaries. Most of the earlier VDCs either in part or whole have become a ward of new rural municipality or municipality.

\section{Data sources and method of analysis}

The present study is based on secondary data sources. Both spatial data and socioeconomic data and information are collected from secondary sources. GIS tool is applied for data mapping and analysis. Economically active population in agriculture is selected as representative census variable for mapping and obtained from census 2011 report (CBS, 2012). Spatial layer of local administrative units' boundary (then, VDCs) is obtained from Survey department of Nepal and agriculture area was derived from the 2010 LANDSAT image of 30 meter spatial resolution. Spatial data layer for newly restructured local level administrative unit boundaries was created by merging old VDC boundaries. Census data available at old VDC level units was aggregated at the new restructured municipality and rural municipality. Both old and new local administrative level data were processed and integrated with corresponding spatial layer for the mapping in the GIS environment. A correlation coefficient of agriculture area and the economically active population in agriculture was calculated for both old and new local units to explore the relationship between existing agricultural land and economically active population engaged in agriculture activities.

A series of maps were created using two different boundaries to explore scale effect and five class range to compare different classification methods to explore the effect of data 
classification methods on spatial representation. Four data classification methods are applied namely, Jenk's natural break, quantiles, equal intervals and geometric intervals. Jenk's natural breaks method minimizes within-class variance and maximizes betweenclass differences (Evans, 1977). Quantiles method classifies data into a number of categories with an equal number of units in each category. In this method, possible values were divided into unequal-sized intervals so that the number of values is the same in each class. Equal Intervals method sets the value ranges in each category equal in size. The entire range of data values (max-min) was divided equally into the chosen number of categories. However, these methods were most accurate for data sets with specific distributional characteristics (Smith, 1986). Geometric intervals is another method which ensures approximately the same number of values with each class and that the change between intervals is fairly consistent, hence map produced is visually appealing. This method is most applied for uneven data distribution (Thomas, 2001).

\section{Result and discussion}

\section{Restructuring of administrative boundary and the scale effect}

The common practice of socio-economic and census data dissemination and analysis is associated with the spatial unit and constituted by an administrative/political boundary. However, data are available for pre-defined boundaries only which may represent census block, ward boundary, village boundary, district boundary etc. Published census data dissemination unit till 2011 in Nepal was VDC boundary, which also served as a lowest level spatial unit of analysis. Due to the restructuring of the administrative boundary at the local level, 2011census data need to be aggregated for the statistical analysis, mapping, and visualization. Previous local level administrative boundary with larger number comprising smaller area (47 units) was restructured into a fewer number covering larger area (12 units). This has the effect of coarsening the resolution of the data, where the average resolution is defined as the square root of the size of the area divided by the number of areal units (Tobler, 1989). The correlation between existing agriculture area and the economically active population in agriculture at two different spatial unit levels was calculated to explore the effect of boundary change in statistical analysis and the result showed the variation. As compared to the old administrative unit boundary with the correlation value of 0.62 , the higher calculated correlation value (0.88) is observed for the restructured spatial unit boundary. Similarly, standard deviation and mean decreased (Table 1). Though not emphasized in most cases, the effect of MAUP is prevalent and important in common statistical analysis such as mean, standard deviation and correlation coefficient when data collected at different spatial levels are used (Openshaw \& Taylor, 1979). In GIS mapping, larger standard deviation shows increasing variability in the area of study which in most cases is not characterized by mean only. 
Table 1: Effect of changing spatial units on the statistical value

\begin{tabular}{|l|r|r|l|}
\hline \multicolumn{1}{|c|}{ Statistics } & $\begin{array}{c}\text { Old } \\
\text { Boundary }\end{array}$ & $\begin{array}{c}\text { New } \\
\text { Boundary }\end{array}$ & \multicolumn{1}{|c|}{ Remarks } \\
\hline Number of spatial units & 47 & 12 & $\begin{array}{l}\text { Restructuring of the old administrative } \\
\text { boundary to new }\end{array}$ \\
\hline Min & 0.0197 & 0.0197 & $\begin{array}{l}\text { No change in boundary: Kanda rural } \\
\text { municipality }\end{array}$ \\
\hline Max & 0.761 & 0.452 & $\begin{array}{l}\text { Variation in value due to a combination } \\
\text { of same aerial data into larger units: } \\
\text { scale effect (Openshaw, 1983) Part of } \\
\text { old local units are merged to create a } \\
\text { new single local unit. }\end{array}$ \\
\hline Standard deviation & 0.341 & 0.277 & $\begin{array}{l}\text { Variation in value due to a combination } \\
\text { of same data aggregated into larger } \\
\text { units (scale effect, Openshaw, 1983) }\end{array}$ \\
\hline $\begin{array}{l}\text { Correlation Coefficient: } \\
\text { Agriculture area and } \\
\text { Economically active } \\
\text { population in Agriculture }\end{array}$ & 0.62 & 0.135 & $\begin{array}{l}\text { Aggregation decreases the value of } \\
\text { standard deviation (Openshaw \& } \\
\text { Taylor, 1979) }\end{array}$ \\
\hline
\end{tabular}

Source: Calculated from GIS

\section{Restructuring of administrative boundary and effect of data classification methods}

Data classification allows visualizing spatial patterns more easily. However, factors related to data classification such as a number of classes, the class range and methods applied changes the boundary between the classes and significantly alter resulting spatial representation of the same area and same data in a map. The effect of restructuring of the local unit boundary is explored through different data classification methods to map census data (Table 2, 3 and Figure $1 \mathrm{~A}-\mathrm{H}$ ). Four different data classification methods were applied to both old and new boundaries. The number of classes and the class range value presented in a table is plotted in corresponding maps. When data classification factors are not considered, the pattern which was not previously detected or existed in reality may be visible. Though, a number of classes are dependent on the objective of the analysis, the rules by which the data is assigned to a class, requires explanation, so those users like policy makers interpret the map correctly and the appropriate decision 
taken. The concentration of number of VDCs in one class group is evident from the Table 2 revealing the uneven distribution of number of VDCs while using equal interval which ranges from only 1 VDC in one class group and 26 in another class group. The current study reveals variation while using different classification method for the same spatial boundary. It is found that Quantile method suited the best with relatively uniform number of VDCs among four classification method while plotted against old (47) local level spatial unit (Table 2). Evans (1977) has suggested the same number of class intervals irrespective of classification methods to examine the difference in spatial pattern. It is also recommended not to use an equal interval for map comparison if purpose is to explore central tendency.

Table 2: Data classification methods plotted against old boundary of Bajhang

\begin{tabular}{|c|c|c|c|}
\hline Method and No. of class & Class Range & No of admin unit per class & Percentage \\
\hline \multicolumn{4}{|l|}{ Jenk's Natural Break } \\
\hline 1 & $0.54-0.64$ & 2 & 4.26 \\
\hline 2 & $0.65-0.79$ & 8 & 17.02 \\
\hline 3 & $0.80-0.86$ & 18 & 38.30 \\
\hline 4 & $0.87-0.91$ & 15 & 31.91 \\
\hline 5 & $0.91-0.98$ & 4 & 8.51 \\
\hline \multicolumn{4}{|l|}{ Quantile } \\
\hline 1 & $0.54-0.79$ & 10 & 21.28 \\
\hline 2 & $0.80-0.85$ & 9 & 19.15 \\
\hline 3 & $0.86-0.87$ & 12 & 25.53 \\
\hline 4 & $0.88-0.90$ & 7 & 14.89 \\
\hline 5 & $0.91-0.98$ & 9 & 19.15 \\
\hline \multicolumn{4}{|l|}{ Equal Interval } \\
\hline 1 & $0.54-0.63$ & 2 & 4.26 \\
\hline 2 & $0.64-0.71$ & 1 & 2.13 \\
\hline 3 & $0.72-0.80$ & 9 & 19.15 \\
\hline 4 & $0.81-0.89$ & 26 & 55.32 \\
\hline 5 & $0.90-0.98$ & 9 & 19.15 \\
\hline \multicolumn{4}{|l|}{ Geometric Interval } \\
\hline 1 & $0.54-0.72$ & 3 & 6.38 \\
\hline 2 & $0.73-0.82$ & 11 & 23.40 \\
\hline 3 & $0.83-0.88$ & 17 & 36.17 \\
\hline 4 & $0.89-0.92$ & 12 & 25.53 \\
\hline 5 & $0.93-0.98$ & 4 & 8.51 \\
\hline
\end{tabular}

Source: Calculated from GIS 
On the other hand, using the same data classification methods with new boundary confirmed a variation in resulting spatial pattern. Though Quantile method suited best for the old boundary, the same classification method did not show significant difference with other classification method. The distribution of number of spatial units didn't vary much between these four methods (Table 3). It is hence, evident that the same data classification method for aggregated data at a higher spatial level reveals the different spatial pattern than with larger number of spatial units. Though not much variation is found among four data classification methods regarding the distribution of number of spatial units, number of studies has suggested Jenk's Natural Break method for comparison (Evans, 1977; MacEachren, 1994). How representative is the attempt to preserve natural spatial pattern is another issue when aggregating data from larger scale (more number of smaller units) to smaller scale with less number of larger units. It is obvious that data based on the geographic boundary and the classification method used to represent them are dependent on the scale and the generalization of features at higher level is an inherent characteristic of data presented at a smaller scale (Flowerdew, 2011).

Table 3: Data classification methods plotted against new boundary of Bajhang

\begin{tabular}{|c|c|c|c|}
\hline Data Class & Data Range & No of admin unit per class & Percentage \\
\hline \multicolumn{4}{|l|}{ Natural Break } \\
\hline 1 & 0.75 & 1 & 8.33 \\
\hline 2 & $0.76-0.83$ & 2 & 16.67 \\
\hline 3 & $0.84-0.85$ & 4 & 33.33 \\
\hline 4 & $0.86-0.88$ & 3 & 25.00 \\
\hline 5 & $0.89-0.91$ & 2 & 16.67 \\
\hline \multicolumn{4}{|l|}{ Quantile } \\
\hline 2 & $0.75-0.83$ & 3 & 25.00 \\
\hline 2 & $0.84-0.85$ & 4 & 33.33 \\
\hline 3 & 0.86 & 2 & 16.67 \\
\hline 4 & $0.87-0.88$ & 1 & 8.33 \\
\hline 5 & $0.89-0.91$ & 2 & 16.67 \\
\hline \multicolumn{4}{|l|}{ Equal Interval } \\
\hline 1 & $0.75-0.78$ & 1 & 8.33 \\
\hline 2 & $0.79-0.81$ & 1 & 8.33 \\
\hline 3 & $0.82-0.85$ & 3 & 25.00 \\
\hline 4 & $0.86-0.88$ & 5 & 41.67 \\
\hline 5 & $0.89-0.91$ & 2 & 16.67 \\
\hline \multicolumn{4}{|l|}{ Geometric Interval } \\
\hline 1 & $0.75-0.80$ & 1 & 8.33 \\
\hline 2 & $0.81-0.83$ & 2 & 16.67 \\
\hline 3 & $0.84-0.85$ & 4 & 33.33 \\
\hline 4 & $0.86-0.88$ & 3 & 25.00 \\
\hline 5 & $0.89-0.91$ & 2 & 16.67 \\
\hline
\end{tabular}

Source: Calculated from GIS 


\section{Restructuring of administrative boundary and data visualization}

Different data classification methods plotted against different boundaries reveal the variation in distribution of number of spatial units while spatial visualization as a map revealed completely distinct pattern (Figure 1 and 2). The 47 spatial units (VDCs) with old boundary were restructured into 12 new local units by merging the number of VDCs for visualizing spatial pattern at two different levels applying the four data classification methods discussed in previous section (Figure 1). Because 47 VDCs were nested under 12 restructured local units, different results from these two levels reflected the scale effect. In theory, zoning should be reflecting the spatial pattern in detail. However, this study shows that zoning particularly, from smaller unit to larger units has blurred the spatial pattern visualization leading to a loss of the preferential information. For instance, four different classes visible under Jenks classification method, while plotted against old spatial unit boundary fell into single class while plotted against new boundary (Figure 1A and 1B). This may have implication for planning and implementation of activities when using only one map. Hence, it is obvious that, data inherent spatial pattern visualization is the functioning of the partitioning system (Wong 2009).

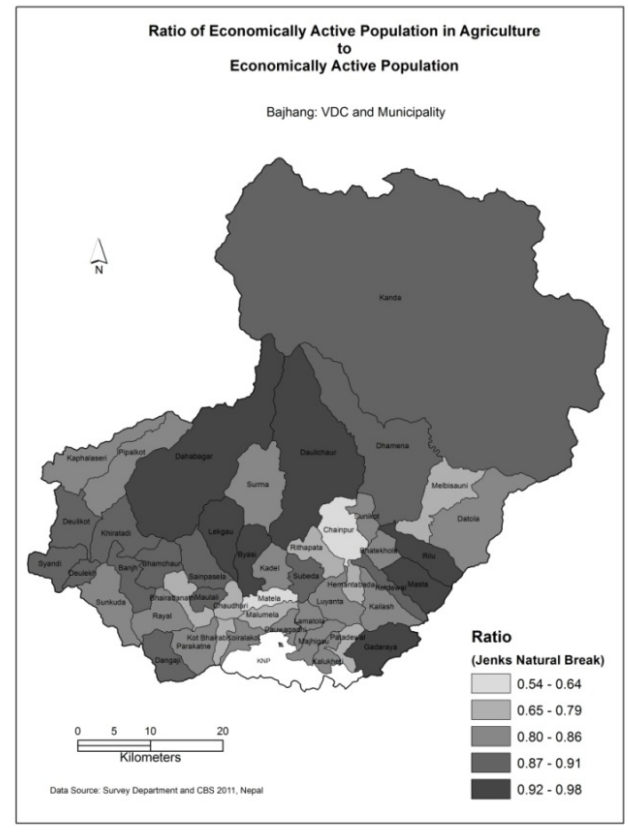

A

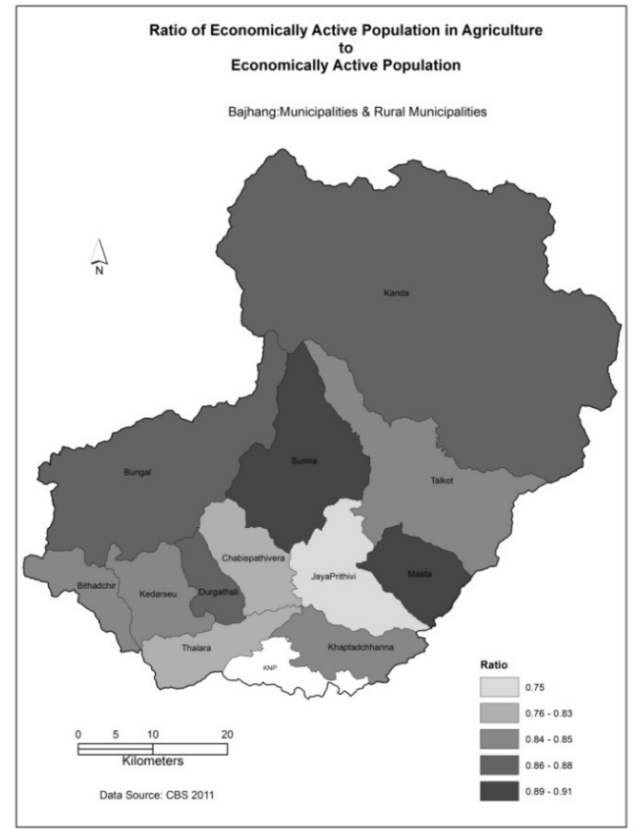

B 
Shobha Shrestha / The Geographical Journal of Nepal Vol. 12: 25-40, 2019

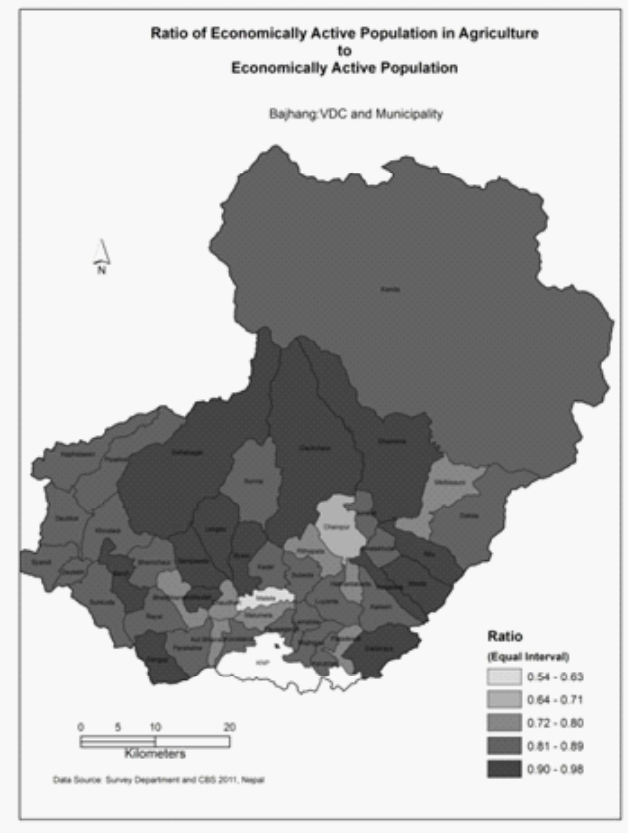

$\mathrm{C}$

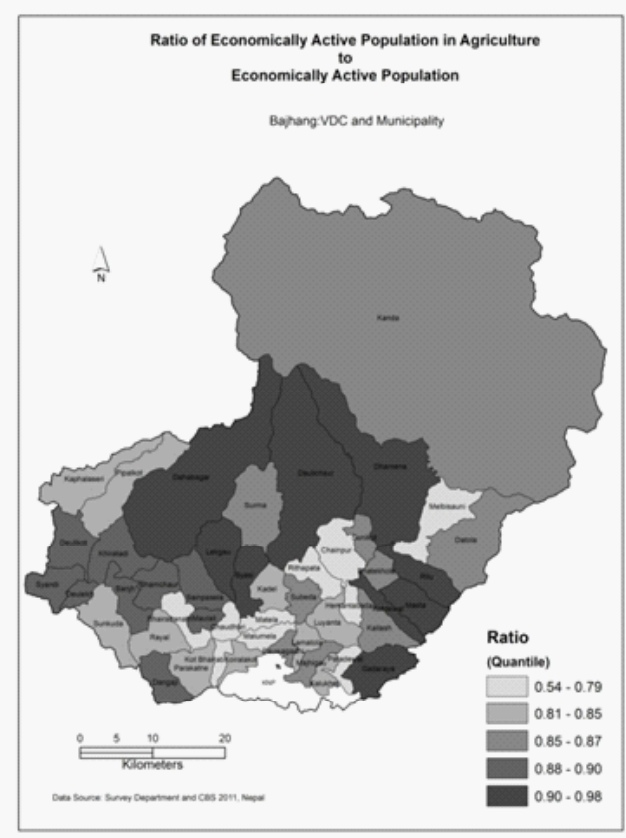

E

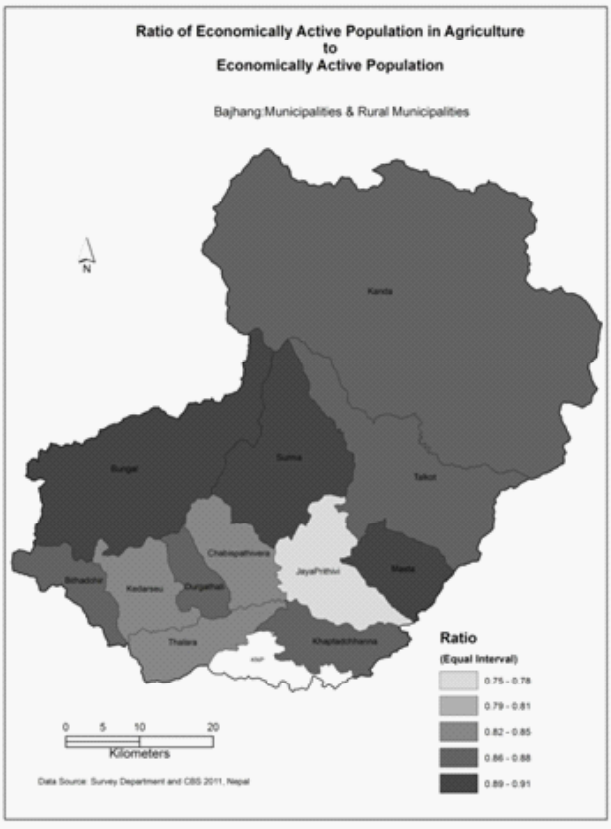

D

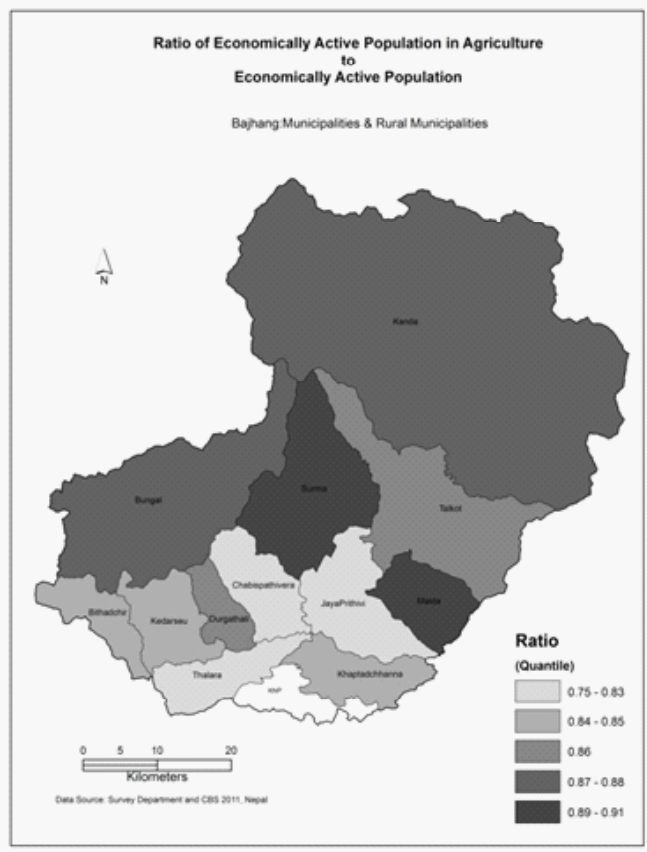

F 


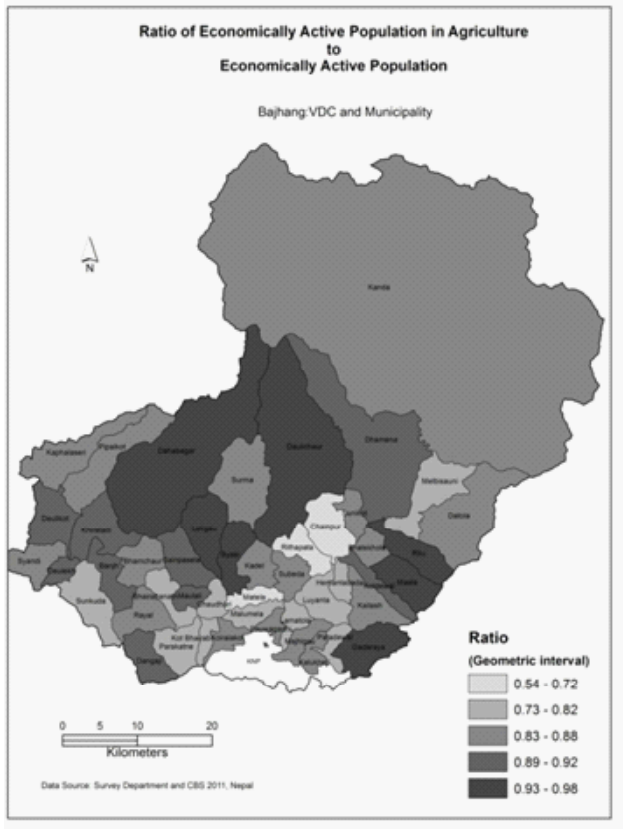

G

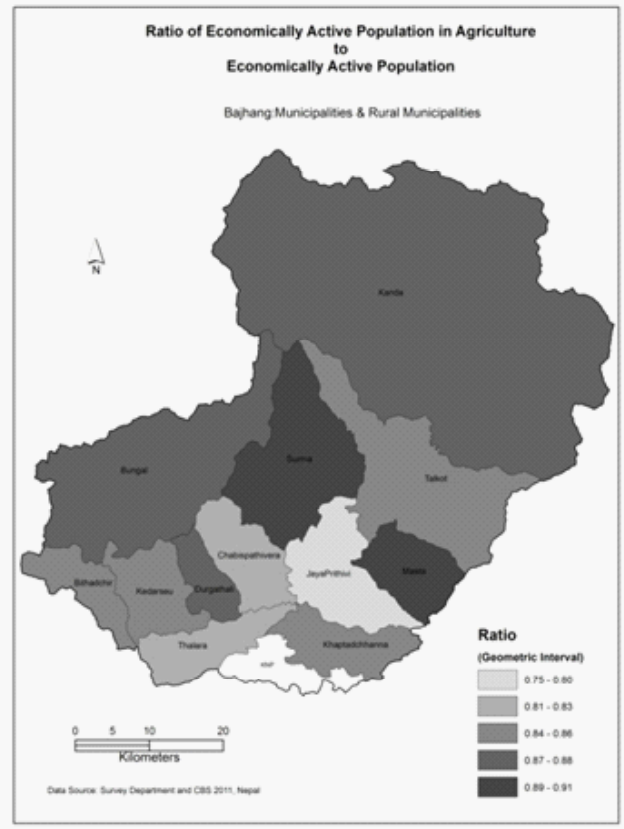

$\mathrm{H}$

Figure1: Visualizing spatial pattern with old and new boundary

A: Jenks natural break: old boundary, B: Jenks natural break: new boundary, C: equal interval: old boundary, D: equal interval: new boundary, E: quantile old boundary, F: quantile: new boundary, G: geometric interval: old boundary and $\mathrm{H}$ : geometric interval: new boundary.

Though there exists the number of methods for zoning or partitioning the space in order to overcome zoning or scale effect, one approach is to use different spatial level mapping and compare the results by aggregating smaller units into lager but heterogeneous units (Smith, 1989; Wooldridge, 2002; Cockings and Martin, 2005). The comparative analysis through the maps produced at the original spatial unit level (old boundary, VDCs) and overlaid with new boundary and maps aggregated at new boundary level help to visualize spatial patterns within the new local units and the district further assisting on decision making (Figure 2). However, application specific solutions have also been proposed to minimize the scale and zoning effect (Tobler, 1989; Wong, 2003; ESPON, 2006). 


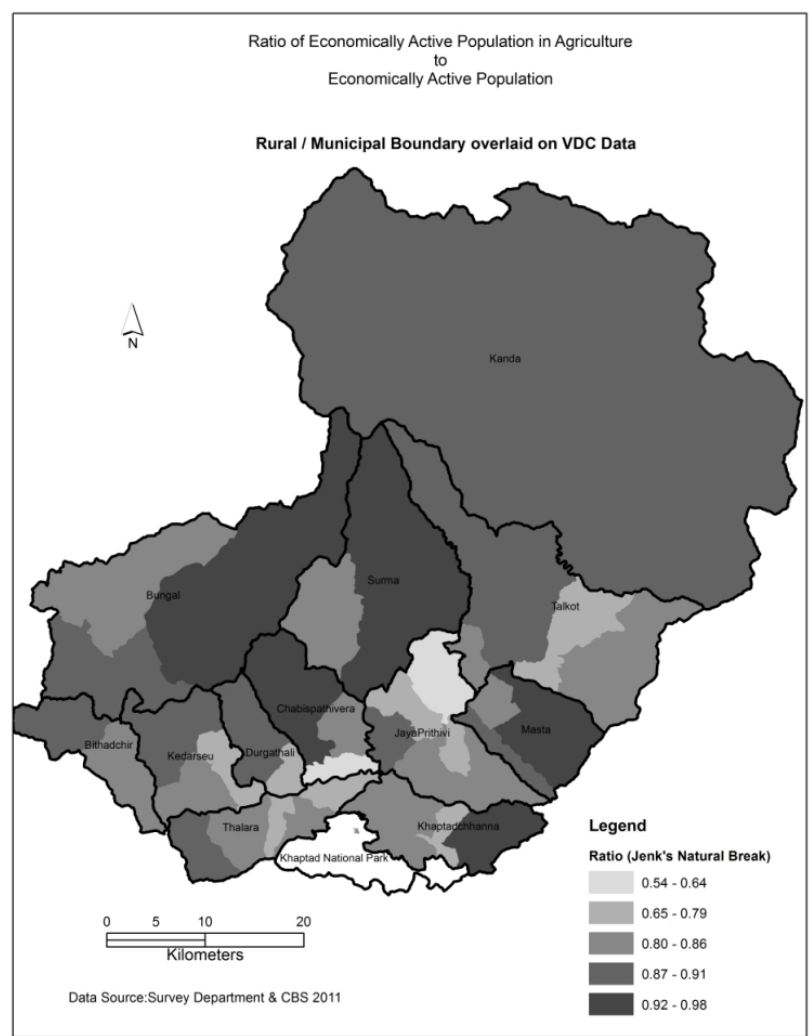

Figure 2: Visualizing spatial variation: Same spatial extent (District boundary) and different spatial zoning (rural municipality and VDCs)

When describing the relationship among variables or analyzing spatial pattern, the dependence of the results on the specific boundary being used should be taken into account while interpreting the maps with data across different spatial levels and different classification methods. The inferences lead to different and sometimes contradictory findings which applied for spatial pattern analysis for any type of planning or policymaking purpose completely distort the existing situation. Not only GIS mapping but with the advent of GIS-based analysis, data are represented as maps. Understanding data analysis concepts become as important as understanding geographic concepts because GIS-based mapping and analysis of socio-economic data are not so much technical as it is social (Barry, 2007). There is common space between data and geographic space because the practice is data distance is used to partition measurement into the separate group while geographic distance is used to partition location into a separate group. Beyond the traditional data analysis, digital mapping provides the data analysis tool which enables to visualize geographic space in abstract form for decision making. 
Partitioning the smallest aggregation units possible into homogeneous regions for a set of attributes that accurately relate to the analytic questions is an effective method for reducing aggregation bias and better decision making because, GIS-based mapping has moved from describing geographic phenomena and resources to prescribing management of resources (Berry, 2007). However, shifting of development projects priorities and decision making in a spatial context is common during the planning process. Results derived from these shifting priorities sometimes cannot be aggregated or nested to provide the meaningful solution or legitimacy or creditability of the project and these are the most necessary attributes for information to cross over from research to policy (Cash et. al., 2006). The effective method of spatial representation and mapping as a planning tool is hence, emphasized (Brenner, 2001; Cash et al., 2006; Cox, 1998; Lebel, 2006; Meadowcroft, 2002; Swyngedouw, 2000). Besides use of methods to minimize scale and zoning effects, another methodological problem has also been discussed while examining the effect of area based attributes which is known to as context based geographic problems (Kwan, 2010).

The consistency of geographic unit at different administrative level is essential for analysis so that long-term designing, planning, and policy implementation is effective. The relationships we can extract from a data set depend both on the scale and space on which the analyses are performed. Further, policies can complicate the situation on geographically targeted population, targeted socioeconomically vulnerable groups if appropriate scales of assessment are not chosen (Stephen and Downing, 2001). The more the level of observation is disaggregated, the easiest it is to construct the zoning that is best adapted to the condition for analyzing and cartographical representations (ESPON, 2006). Spatial patterns inherent to data and geographic space can successfully be explored by using and comparing studies at different levels.

\section{Conclusion}

Development planning and policy implementation are more likely to achieve effective outcome when the problem is analyzed and addressed at the detailed and most appropriate spatial level. However, selecting the most appropriate spatial scale is always challenging. In the current state, though ward is the lowest spatial unit for local administration and service delivery, it is not the lowest spatial unit for census data dissemination. If the coming census 2021 is planned at disseminating data at ward level, the administrative level will be lower but the spatial coverage will remain the same as earlier VDCs. The restructuring of administrative boundaries into larger unit has simplified the detail for spatial representation and hence has introduced additional generalization of census data. If the lowest possible spatial level is not chosen for assessment, it may have implication on policies, either geographically targeted at socioeconomically vulnerable groups or to the area of natural disasters. Use of data available at one level of the spatial unit for 
policy level analysis when aggregated to higher level should be analyzed carefully using different data classification methods and visualization tools. It is concluded that scaled spatial representation matters in planning and policy aspect. It has policy significance and hence careful mapping and interpretation is essential. It is also essential to identify lowest level spatial unit for data analysis and visualization. It is suggested that with the restructuring of the administrative boundary, disaggregated data at a lowest spatial level than existing wards should be provided for meaningful spatial representation, careful analysis, and better development planning. Visual-spatial decision making should be enriched with preferential information and GIS as a tool should and GIS mapping as a method should be devised carefully. It is meaningful to analyze data at different spatial scale to visualize and identify spatial variation.

\section{References}

Barry, J. (2007). Map analysis: Understanding spatial patterns and relationships. GeoTecMedia. Denver, US.

Bell, N. \& Schuurman, N., (2010). GIS and injury prevention and control: History, challenges, and opportunities. International Journal of Environmental Research and Public Health. 7 (1), 1002-17. DOI:10.3390/ijerph7031002.

Brenner, N., (2001). The limits to scale? Methodological reflections on scalar structuration. Progress in Human Geography, 25 (1), 591-614.

Cash, D. W., Adger, W., Berks, F., Garden, P., Lebel, L., Olsson, P., Pritchard, L. \& Young, O. (2006). Scale and cross-scale dynamics: Governance and information in a multilevel world. Ecology and Society, 11 (2):8. http://www.ecologyandsociety. org/vol11/iss2/art8/.

CBS (2012). National population and housing census 2011: District Profiles. Central Bureau of Statistics, CBS, National Planning Commission, Kathmandu, Nepal.

Cocking, S., and Martin, D. (2005). Zone design for environment and health studies using pre-aggregated data. Social Science and Medicine. 60 (12): 2729-2742.

Cheng, J., Turkstrab, J., Pengc, M., Dud, N. \& Ho, P. (2006). Urban land administration and planning in China: Opportunities and constraints of spatial data models. Land Use Policy, 23 (2006) 604-616.

Cox, K. R. (1998). Spaces of dependence, spaces of engagement and the politics of scale, or: looking for local politics. Political Geography, 17(1), 1-23.

DDC, Bajhang. (2014). Bajhang district profile, 2014. District Development Committee Office, Bajhang.

ESPON. (2006). The modifiable areas unit problem: A final report. ESPON Scientific Support Project.European Union, ESPON Coordination Unit, Luxembourg. 
Evans, I. A. (1977).The selection of class intervals. Institute of British Geographers Transactions, New Series 2 (1): 98-124.

Flowerdew, R. (2011). How serious is the modifiable areal unit problem for analysis of English census data? Population Trends. No 145.

Fox, K. (2010). The use of census data for national development planning. Studies and perspectives series, United Nations Publications, Chile.

Gehlke, C. E., and Biehl, K.(1934).Certain effects of grouping upon the size of the correlation coefficient in census tract material. Journal of the American Statistical Association Supplement 29: 169-170.

Jelinski, D. E. and Wu, J. (1996). The modifiable areal unit problem and implications for landscape ecology, Landscape Ecology. June 1996, 11 (3), 129-140.

Kwan, M. P. (2012). The uncertain geographic context problem. Annals of the Association of American Geographers, 102(5), pp. 958-968.

Lebel, L. (2006). The politics of scale in environmental assessments. In: Reid, W., V., Berkes, F., Wilbanks, T. J. \& Doris, C. (eds.) Bridging Scales and Knowledge Systems: Concepts and Applications in Ecosystem Assessment. Washington: Island Press.

MacEachren, A. M. (1994). Some truth with maps: A primer on symbolization and design. Association of American Geographers, AAG, Washington DC.

Meadowcroft, J. (2002). Politics and scale: some implications for environmental governance. Landscape and Urban Planning, 61 (1), 169-179.

MoFALD, (2018). Brief introduction of rural municipality and municipality (In Nepali: Gaunpalika tatha nagarpalika ko sanchhipta parichaya pustika, 2074). Ministry of Federal Affairs and Local Development, MoFALD, Government of Nepal.

MoLJPA, (2017). The constitution of Nepal. Ministry of Law, Justice and Parliamentary Affairs, Government of Nepal.

National Research Council. (1997). Rediscovering geography: New relevance for science and society. Washington, DC: The National Academies Press.

Openshaw, S., and Alvanides, S. (2005). Applying geo-computation to the analysis of spatial distributions. In Longley, P. A., Goodchild, M. F., Maguire, D. J. and D. W. (eds.) Geographical Information Systems: Principles, Techniques, Management and Applications, Abridged 2nd Edition, New Jersey :John Wiley and Sons Inc..

Openshaw, S. (1996). Developing GIS-relevant zone-based spatial analysis methods. In:Spatial Analysis: modeling in a GIS environment, Longley P. and Batty M. (eds.), New-York, John Wiley: 55-73. 
Openshaw, S., Taylor, P., (1979). A million or so correlation coefficients: three experiments on the modifiable areal unit problem, Statistical Applications in the Spatial Sciences. London: Ed. N Wrigley.

Paez, A. and Scott, D. M., (2005). Spatial statistics for urban analysis: A review of techniques with examples. Geo Journal, 61(1):53-67.

Smith, R. M. (1986). Comparing traditional methods for selecting class intervals on choropleth maps. The Professional Geographer. 38(1):62-67.

Smith, TMF. (1989). Aggregated analysis: Point estimation and bias. In: Skinner, CJ.; Holt, D.; Smith, TMF. (eds.) Analysis of complex surveys. p. 135-47. New York: Wiley.

Stephen, L. and Downing, T.E., (2001). Getting the scale right: a comparison of analytical methods for vulnerability assessment and household-level targeting. Disasters, 25(2): 113-135.

Swyngedouw, E. (2000). Authoritarian governance, power, and the politics of rescaling. Environment and Planning D. 18 (1), 63-76.

Thomas, I. (2001). Thematic cartography today: recalls and perspectives. Cybergeo: European Journal of Geography, 189: 1-24.

Tobler, W (1989). Frame independent spatial analysis. In Accuracy of Spatial Databases, Goodchild, M. F. and Gopal, S. (eds.). London: Taylor and Francis.

Veldhuizen, E. and Pfeffer, K. (2016). Crossing boundaries: mapping spatial dynamics of urban phenomena at micro scale to support urban management in the Amsterdam urban region, Belgeo, Belgian Journal of Geography, 2. DOI : 10.4000/belgeo. 17740 .

Wakefield, J. and Lyons, H. (2010).Spatial aggregation and ecological fallacy. Gelfand, AE.,Diggle, PJ., Fuentes, M. and Guttorp, P.(eds.) Handbook of Spatial Statistics. New York: CRC Press, Taylor \& Francis Group.

Wall, H. (2008). Development of a national policy framework for census data dissemination utilizinga geographic data management systems (GDMS). Unpublished research seminar paper, Common Census Framework, Caribbean Community (CARICOM) Secretariat.

Wong, D. (2009). The modifiable areal unit problem (MAUP). In Fotheringham A.S and Rogerson, P.A. (eds). The SAGE Handbook of Spatial Analysis. London: Sage Publications Ltd.

Wong, D. (2003). Spatial decomposition of segregation indices: A framework toward measuring segregation at multiple levels. Geographical Analysis, 35 (3), 179-194. 